\title{
Immunochemical characterization of polysaccharide antigens from six clinical strains of Enterococci
}

\author{
Carolyn T Hsu' ${ }^{1}$, Amanda L Ganong ${ }^{1}$, Barbara Reinap ${ }^{1}$, Zafiria Mourelatos ${ }^{1}$, \\ Johannes Huebner ${ }^{1,2}$ and Julia Y Wang*1
}

Address: ${ }^{1}$ Channing Laboratory, Department of Medicine, Brigham and Women's Hospital, Harvard Medical School, Boston, MA02115, USA and ${ }^{2}$ Division of Infectious Diseases, Department of Medicine, University Hospital Freiburg, Germany

Email: Carolyn T Hsu - hsutlc@gmail.com; Amanda L Ganong - amanda@toxicteeth.org; Barbara Reinap - breinap@ rics.bwh.harvard.edu; Zafiria Mourelatos - rmourelatos@hotmail.com; Johannes Huebner - johannes.huebner@uniklinik-freiburg.de; Julia Y Wang* - julia_wang@rics.bwh.harvard.edu

* Corresponding author

Published: 12 July 2006

BMC Microbiology 2006, 6:62 doi:10.1/86/147|-2180-6-62
Received: 24 March 2006

Accepted: 12 July 2006

This article is available from: http://www.biomedcentral.com/I47I-2/80/6/62

(c) 2006 Hsu et al; licensee BioMed Central Ltd.

This is an Open Access article distributed under the terms of the Creative Commons Attribution License (http://creativecommons.org/licenses/by/2.0), which permits unrestricted use, distribution, and reproduction in any medium, provided the original work is properly cited.

\begin{abstract}
Background: Enterococci have become major nosocomial pathogens due to their intrinsic and acquired resistance to a broad spectrum of antibiotics. Their increasing drug resistance prompts us to search for prominent antigens to develop vaccines against enterococci. Given the success of polysaccharide-based vaccines against various bacterial pathogens, we isolated and characterized the immunochemical properties of polysaccharide antigens from five strains of Enterococcus faecalis and one strain of vancomycin-resistant $E$. faecium.

Results: We cultured large batches of each strain, isolated sufficient quantities of polysaccharides, analyzed their chemical structures, and compared their antigenic specificity. Three classes of polysaccharides were isolated from each strain, including a polyglucan, a teichoic acid, and a heteroglycan composed of rhamnose, glucose, galactose, mannosamine, and glucosamine. The polyglucans from all six strains are identical and appear to be dextran. Yields of the teichoic acids were generally low. The most abundant polysaccharides are the heteroglycans. The six heteroglycans are structurally different as evidenced by NMR spectroscopy. They also differ in their antigenic specificities as revealed by competitive ELISA. The heteroglycans are not immunogenic by themselves but conjugation to protein carriers significantly enhanced their ability to induce antibodies.

Conclusion: The six clinical strains of enterococci express abundant, strain-specific cell-surface heteroglycans. These polysaccharides may provide a molecular basis for serological typing of enterococcal strains and antigens for the development of vaccines against multi-drug resistant enterococci.
\end{abstract}

\section{Background}

Enterococci are part of the normal flora of the gastrointestinal and genitourinary tracts and colonize the bowels of more than $90 \%$ of healthy humans [1]. Enterococci are opportunistic pathogens with generally low virulence, but their intrinsic and increasing acquired resistance to multiple drugs have made them a major cause of nosocomial infections $[2,3]$. Enterococci are intrinsically resistant to a 
number of antimicrobial drugs, including cell wall-active agents, many commercially available aminoglycosides, and vancomycin - the antibiotic of last resort against multidrug-resistant bacteria [4-7]. Enterococci can cause severe invasive infections such as peritonitis, endocarditis, meningitis, and abscesses in the urinary tract, along surgical sites, the lung and pleural spaces, facial sinuses, and peritoneal cavities $[8,9]$. Because enterococci can spread rapidly among hospital patients and transfer their antibiotic resistance genes widely, even to other bacterial species, they may cause epidemics difficult to control and thus pose a significant threat to public health. The everincreasing resistance of enterococci to multiple drugs prompts us to search for prominent antigens for the development of vaccines.

Enterococci are Gram-positive cocci that share morphology and Lancefield antigenicity with group D streptococci. Invasive Gram-positive pathogens, such as Streptococcus pneumoniae, are often encapsulated with weakly immunogenic polysaccharides (PSs). These PSs are major virulence factors. It has been found that the structural differences between capsular PSs form the molecular basis of serologic specificity for many species such as $S$. pneumoniae [10]. Specific antibodies to $S$. pneumoniae PSs promote opsonization and phagocytosis and thereby confer protection against pneumococcal infection. Many successful antibacterial vaccines, such as ones against various serotypes of $S$. pneumoniae, type b of Haemophilus influenzae, and group $\mathrm{C}$ of Neisseria meningitides, have been developed based on their capsular PSs; and many other polysaccharide-based vaccines are under development [11]. PSs and PS-synthesis genes have been noted to be widespread among enterococcal strains [12-15]. Enterococcal PSs have been demonstrated to play important roles in enterococcal pathogenesis, such as conferring resistance to phagocytosis [16]. Furthermore, enterococcal PSs have been proposed as promising vaccine antigens [17-19].

Among enterococcal species, Enterococcus faecalis and E. faecium are the two major human pathogens, accounting for $85-89 \%$ and $10-15 \%$ of all enterococcal infections, respectively $[8,9]$. Previous investigations have revealed that enterococci express surface PSs analogous to capsules of other pathogenic bacteria [20-23]. However, only a few types of enterococcal PSs have been characterized with respect to their structure and antigenicity, and then only partially so. It is not known whether strains of enterococci express different PSs, nor how many types of PSs exist within the enterococci family. On the hypothesis that cellsurface PSs of enterococci form an antigenic basis for serotyping and are promising vaccine candidates, we investigated and compared the immunochemical properties of PSs from six clinical strains of enterococci, including five strains of $E$. faecalis and one strain of vancomycin-resistant E. faecium.

\section{Results}

Three different PSs were isolated from each enterococcal strain

To ease the PS isolation and purification, bacteria of each enterococcal strain were grown in dialyzed Columbia broth containing only nutrients with size less than 10 $\mathrm{kDa}$, which were removed by dialysis later in the purification process. PSs, released by bacterial cells during fermentation, were found negligible when we attempted to isolate the PSs from the culture medium. Therefore, all PSs characterized in this study are cell-attached.

Of various enterococcal strains examined in this and our unpublished studies, three pools of PSs were obtained from each of the six enterococcal strains, eluting from the size-exclusion Sephacryl S400 column in the same order (Fig. 1). The first PS eluted close to the void volume. As determined by GC-MS analysis of its alditol acetate derivative (data not shown), this PS consists solely of glucose. Based on its $1 \mathrm{D}^{1} \mathrm{H}$ and $2 \mathrm{D}{ }^{1} \mathrm{H}-{ }^{13} \mathrm{C}$ HMQC spectra (data not shown $)$, this PS is a poly- $\alpha$-D- $(1 \rightarrow 6)$-glucose, i.e., dextran. Dextran was found in all six enterococcal stains in this study and also in other enterococcal strains (unpublished results). The second PS consisted of disaccharide repeating units as suggested by NMR analysis. Because of the low yield of this PS, it was difficult to conduct further analysis. However, we speculate this PS might be consistent with the previously identified teichoic acid [24]. The third PS is a complex heteroglycan, as revealed by NMR, and its structure varies among different strains (see below). The heteroglycans were the most abundant PSs isolated from each enterococcal strain. They are relatively small, with average molecular sizes of $\sim 20 \mathrm{kDa}$, as compared with the dextran standards.

When blotted with sera raised against whole bacterial cells, column-eluting fractions corresponding to the dextran-like PS and the teichoic acids were reactive. Because the dextan-like PS fractions were contaminated with proteins, the immune reactivity is most likely due to the contaminants but not the PS. The reactivity of teichoic acids with immune sera is consistent with previous findings [23]. The heteroglycans did not react with immune sera raised against the whole bacterial cells, indicating that these PSs are not natively immunogenic on the enterococcal cell surface.

\section{Chemical structural analysis of heteroglycans}

Monosaccharide composition of the heteroglycans was identified by GC-MS analysis of their corresponding alditol acetate derivatives. The analysis revealed that the heteroglycans isolated from the six strains of $E$. faecalis and $E$. 


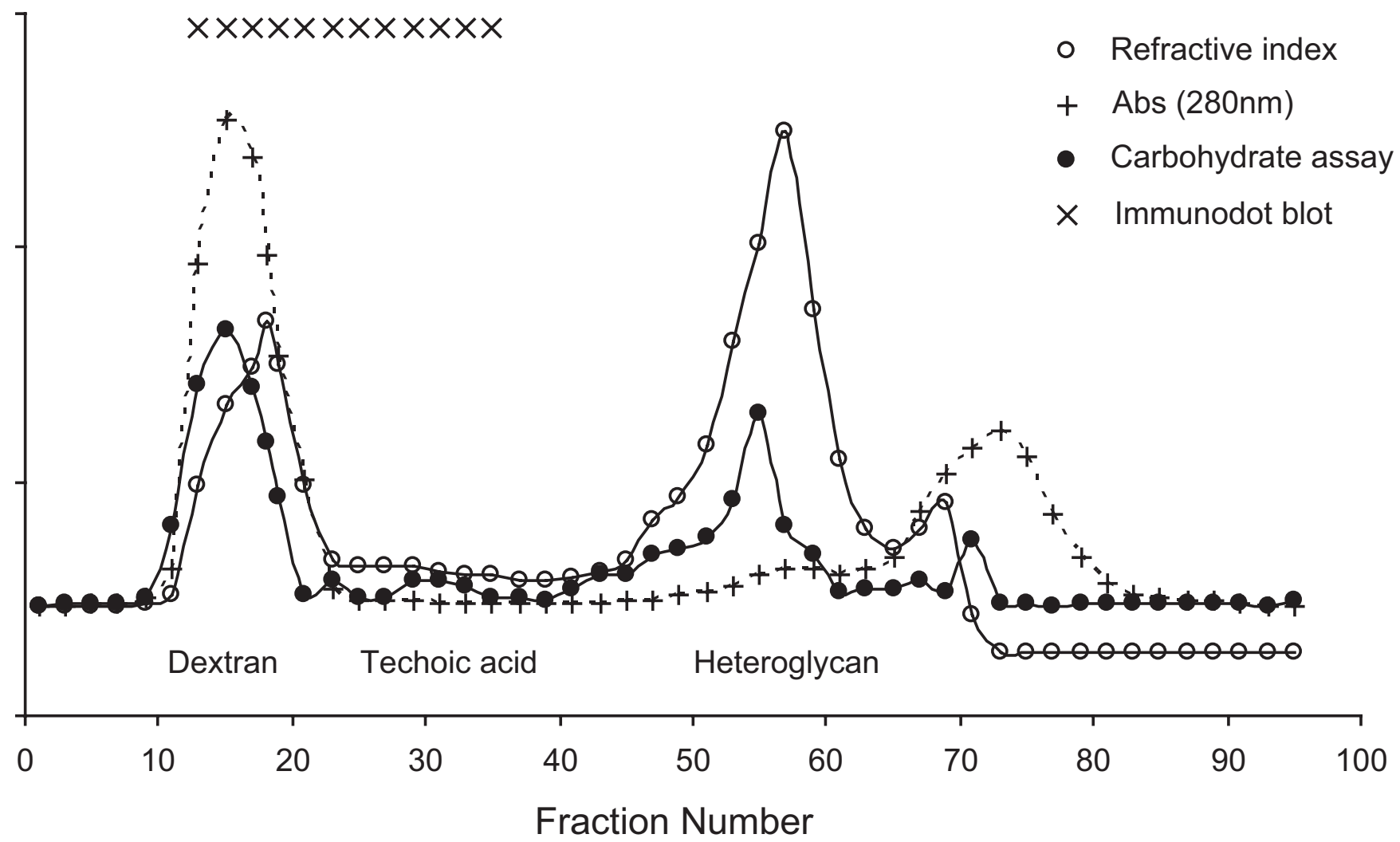

Figure I

A typical Sephacryl S400 column elution profile of the three PSs isolated from E. faecium B2 I 0860 . Elution profiles from the five $E$. faecalis strains are similar. Fractions positive in immunodot blotting with antiserum raised with $E$. faecium B2 10860 cells are indicated. The dextran fractions are contaminated with proteins as revealed by UV absorbance at $280 \mathrm{~nm}$. The heteroglycan fractions are protein-free, positive in carbohydrate assay, and do not react with antisera induced by bacterial cells.

faecium contained the same five monosaccharides, namely, rhamnose, glucose, galactose, mannosamine, and glucosamine. Furthermore, the mannosamine and glucosamine residues were $\mathrm{N}$-acetylated as suggested by NMR analysis. Although these PSs contain the same components, five monosaccharides can form an enormous number of differently structured PSs by varying their sequences and linkage sites. Therefore, we relied on NMR spectroscopy to distinguish these PSs.

The heteroglycans from the six enterococcal strains display distinct patterns on their ${ }^{1} \mathrm{H}-\mathrm{NMR}$ spectra (Fig. 2). In each spectrum, signals between 5.6 and 4.5 ppm correspond to the anomeric protons of the monosaccharide components of the PS, and these signals often serve as signatures for differentiating complex carbohydrate structures. The signals between 4.4 and $3.2 \mathrm{ppm}$ are due to protons attached to $\mathrm{C} 2-\mathrm{C} 6$ and are poorly resolved due to the overlapping chemical shifts. The pattern of these signals, nonetheless, also reveals the similarities and differ- ences between PSs. The signals at $\sim 2.1 \mathrm{ppm}$, resulting from the methyl protons of $\mathrm{N}$-acteyl or $\mathrm{O}$-acetyl groups, clearly show the different degree of acetylation of each PS. In addition, the signals at $1.3 \mathrm{ppm}$ that arise from the C- 6 methyl protons of rhamnose are indicative of difference or similarity of the rhamnose component of the PS. Overall, the NMR spectral patterns revealed that the PSs from E. faecium B210860 and E. faecalis strains 324057B, type II, type V, and R19001 are different. However, the PSs from $E$. faecalis strains type $\mathrm{V}$ and 68114 have very similar structure (Fig. 2, bottom two figures). It is possible, in fact, that these two PSs are identical. The structural elucidation of these PSs is quite complicated and is part of an ongoing study.

\section{Immunological characterization of heteroglycans}

To verify the antigenic specificity of the six heteroglycans, we obtained polyclonal antibodies against the heteroglycan PSs from E. faecium B210860 and E. faecalis type V. Because these PSs are not immunogenic in its native form, 

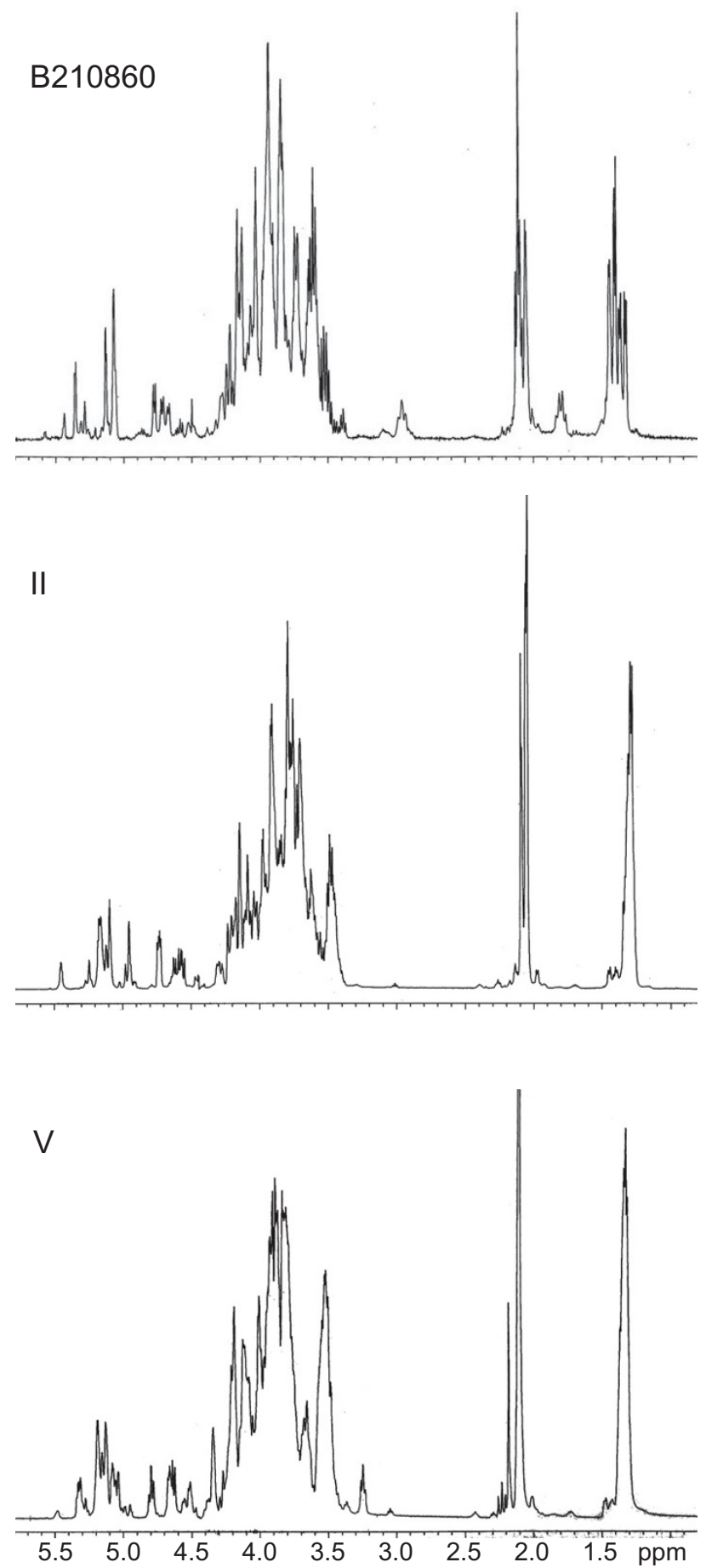
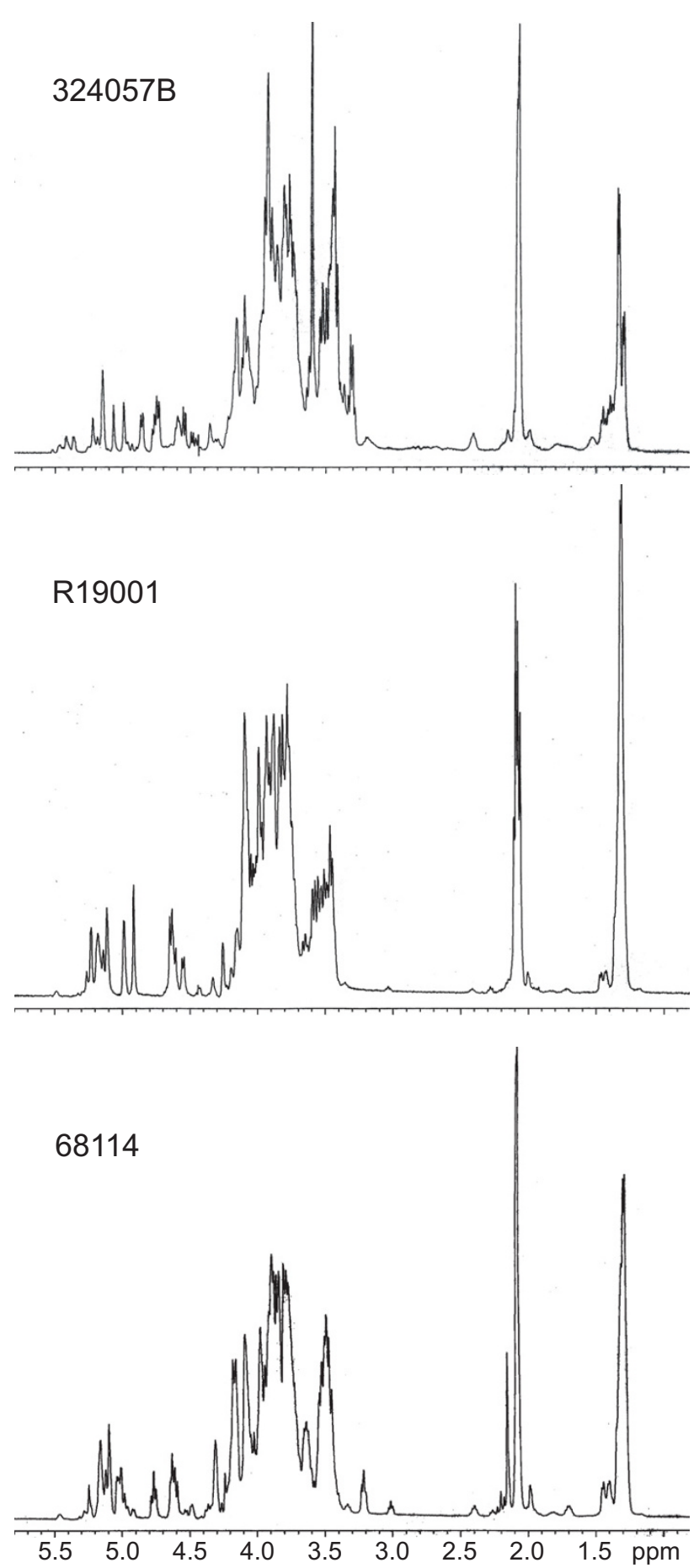

Figure 2

Proton NMR spectra of the heteroglycan PSs from six enterococcal strains. The different signal patterns indicate different structures. The PSs from strain $\mathrm{V}$ and $68 \mathrm{II} 4$ have very similar spectra. Note that the signals at $\sim 2.1 \mathrm{ppm}$ are due to $\mathrm{N}$ or O-acetyl groups and that the difference in intensity and pattern reveal different acetylation of each PS. Also note that the water signal at $4.45 \mathrm{pm}$ has been suppressed in all spectra. 

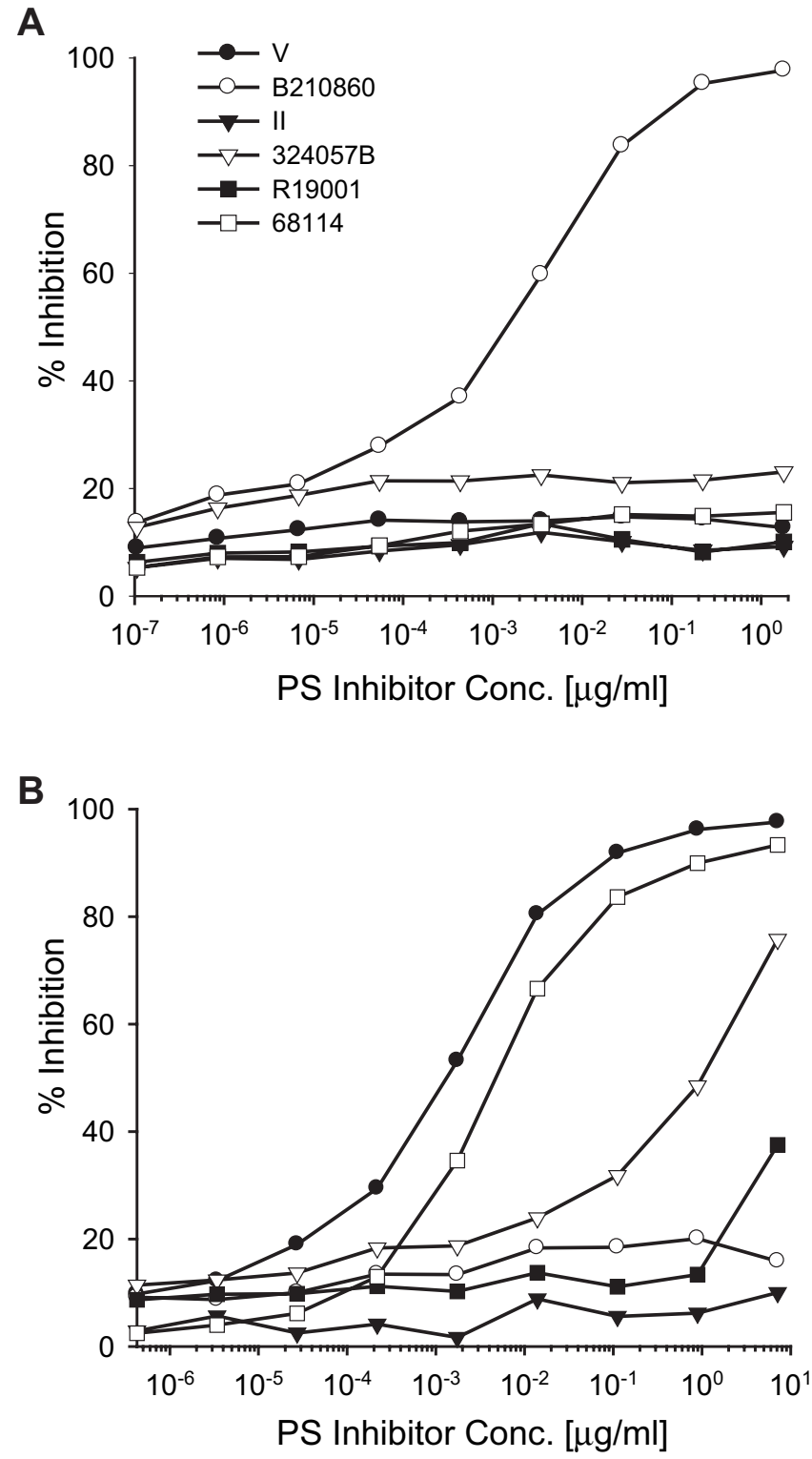

Figure 3

Antigenic specificity of enterococcal heteroglycans. Competitive ELISA inhibition of the binding between $E$. faecium B2 10860 PS and its specific antibodies (A) and inhibition of the binding between $E$. faecalis type $V$ PS and its specific antibodies (B). Starting dilution of inhibitors were 10 times the coating concentrations.

they were conjugated to tetanus toxoid. Both conjugates induced high titers of specific antibodies against the PSs. Therefore, the immunogenicity of these PSs can be significantly enhanced by conjugation to immunogenic protein carriers. If their specific antibodies are proven protective in future investigation, these PSs will become promising antigen candidates for enterococcal vaccines.
The antisera specific for PSs of E. faecium B210860 or E. faecalis type $\mathrm{V}$ were used to probe the antigenic specificity of PSs from different enterococcal strains. The ability to inhibit the binding between these PSs and their specific antibodies by each of the six PSs was determined by competitive ELISA inhibition. As shown in Figure 3A, the results of the ELISA study indicate that the PS from the vancomycin-resistant E. faecium B210860 is significantly different from E. faecalis PSs. The binding between E. faecium B210860 PS and its antisera was only completely inhibited by itself. PSs from E. faecalis type II, 68114, and R19001 did not inhibit this binding even at high PS concentrations. Some batches of PSs from E. faecalis 324057B and type $\mathrm{V}$ displayed limited inhibition at high concentrations.

On the other hand, the binding between E. faecalis type $\mathrm{V}$ PS and its specific sera could be inhibited to various percentages by the PS from E. faecalis strain 68114, 324057B, and R19001 (Fig. 3B). E. faecalis type II PS showed minimal cross-reactivity with type V PS, supporting the contention that these two strains belong to different serotypes. PS from the vancomycin-resistant E. faecium B210860 did not show cross-reactivity with the type V PS, which was confirmed in both inhibition assays (Figs. 3A and 3B). PS from E. faecalis 68114 is highly cross-reactive with PS type V (Fig. 3B). Thus, both inhibition experiments and NMR analysis revealed that PSs from E. faecalis type $\mathrm{V}$ and 68114 are highly similar in structure and antigenicity. It is possible that these two PSs are the same antigen and that the subtle difference is the result of minor contamination in these PS preparations.

This study reveals that all six enterococcal strains express three types of PSs, namely, a large dextran-like polyglucan, a medium-sized teichoic acid, and a heteroglycan with average molecular size of $\sim 20 \mathrm{kDa}$. This result is in line with early findings that the PS gene cluster is widespread among E. faecalis strains and that E. faecalis produces several large and small PSs [13,22]. We are particularly interested in the heteroglycan PSs, because they are the most abundant PSs isolated from all six strains. We also confirmed that the heteroglycans are located at the cell surface by immunofluoresence spectroscopy (Fig. 4) although these heteroglycans could be part of the capsule, cell wall, or both.

\section{Discussion}

Various capsular or cell wall enterococcal PSs have been reported. In 1963, Wicken and Baddiley identified an intracellular glycerol teichoic acid containing various glucose substituents as the group antigen for group D streptococci, to which enterococci previously belonged [25]. In 1973, Pazur et al. characterized an antigenic PS from $E$. faecalis consisting of a main chain of trisaccharide units 


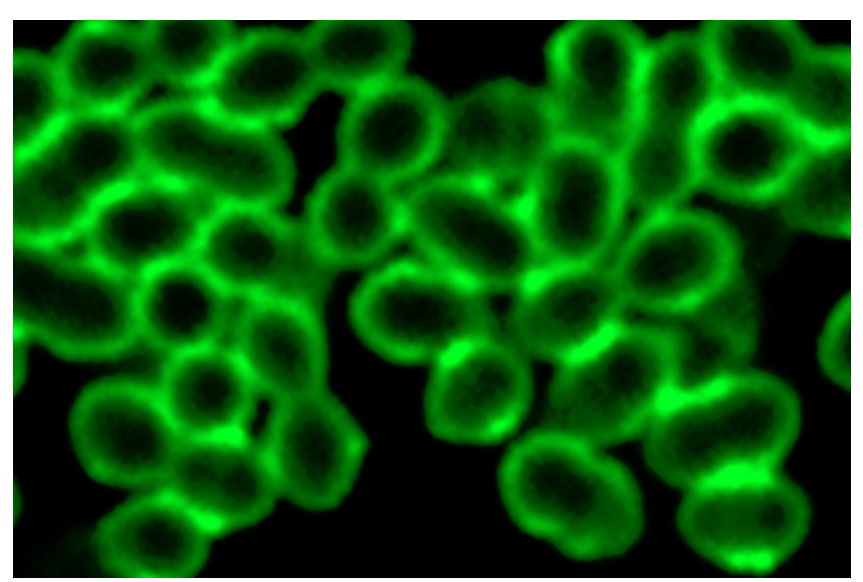

Figure 4

Cell surface location of enterococcal heteroglycans. Confocal micrograph of $E$. faecalis type $V$ labeled with rabbit antisera specific for type $V$ heteroglycan PS is show as an example. Note that these PSs are located at the cell surface.

joined with lactosyl and cellobiosyl side chains [26]. In 1967, Bleiweis et al. reported a type 1 antigen containing glucose, rhamnose, glucosamine, galactosamine, ribitol, and phosphorus [27]. In 1999, we characterized a teichoic acid consisting of glucose, glycerol, and phosphate common to several enterococcal strains $[23,24]$. Recently, Hancock et al. suggested that rhamnopolysaccharides consisting of rhamnose, glucose, galactose, glucosamine, and galactosamine are an invariant component of $E$. faecalis cells $[22,28]$. It is possible that the rhamnopolysaccharides and the heteroglycans in our study belong to the same category, e.g., they are both expressed at a similar cell surface location or serve similar functions in enterococcal physiology or pathogenesis.

\section{Conclusion}

We have isolated and characterized the chemical and immunological properties of various PSs from six clinical strains of E. faecium and E. faecalis. Each strain produces large amounts of a complex heteroglycan consisting of glucose, galactose, rhamnose, N-acetyl-mannosamine, and $\mathrm{N}$-acetyl-galactosamine. These PSs are not natively immunogenic but can be converted to potent immunogens by conjugation to protein carriers. Analysis by NMR spectroscopy and antigenicity analysis by competitive ELISA inhibition revealed that heteroglycan PSs from $E$. faecium B210860 and E. faecalis types II and V are distinct antigens. PSs from E. faecalis strains 324057B and R19001 share some epitopes with type $\mathrm{V}$, whereas $E$. faecalis 68114 PS is highly cross-reactive with type V PS. It is our hope that the heteroglycans may be used as the molecular basis for serotyping enterococcal strains and candidate antigens for the development of vaccines against multi-drug resistant enterococci.

\section{Methods \\ Strain collection}

A total of six clinical enterococcal strains were selected from a collection of clinical isolates. E. faecalis 68114 and vancomycin-resistant E. faecium B210860 were isolated from patients at the Brigham and Women's Hospital in Boston [23]. E. faecalis 324057B was isolated from a patient at the Beth Israel Deaconess Medical Center in Boston [23]. E. faecalis R19001 was an epidemic strain obtained from Boston Children's Hospital [29]. E. faecalis type II and type V strains were isolated from patients in various hospitals in Japan [30]. All isolates were grown in THB broth and 100- $\mu$ l aliquots were stored in THB broth with $10 \%$ glycerol at $-80^{\circ} \mathrm{C}$.

\section{Bacterial culture}

To obtain sufficient amounts of PSs for chemical and immunological analysis, 16-L batch cultures were prepared for each strain in 20-L carboys with Columbia dialysate broth supplemented with 5\% glucose and $0.005 \%$ hemin. The dialysate broth was prepared by dialyzing Columbia broth (Difco Laboratories, Detroit, MI) in deionized water with a membrane of $10 \mathrm{kDa}$ cut-off to remove molecules larger than $10 \mathrm{kDa}$. The $\mathrm{pH}$ of the growth medium were maintained between 7 and 7.2 by titration with $10 \mathrm{M} \mathrm{NaOH}$ through an automatic $\mathrm{pH}$ controller (Cole-Parmer Instrument, Vernon Hills, IL), and the fermentation was terminated when the $\mathrm{pH}$ of the growth medium stabilized without addition of $\mathrm{NaOH}$. Bacteria were typically grown at $37^{\circ} \mathrm{C}$ for $16-24 \mathrm{~h}$. Culture samples were examined for contamination by Gram staining.

\section{Isolation and purification of PSs}

Bacterial cells were harvested by centrifugation at $4{ }^{\circ} \mathrm{C}$ and washed in phosphate-buffered saline (PBS, $0.05 \mathrm{M}$ phosphate, $0.15 \mathrm{M} \mathrm{NaCl}, \mathrm{pH} 7)$. PSs were released from cell pellets by digestion with mutanolysin $(50,000$ units of enzyme per $100 \mathrm{~g}$ of wet cell) at $37^{\circ} \mathrm{C}$ for $16 \mathrm{~h}$ in $250 \mathrm{ml}$ of buffer containing $40 \%$ sucrose, $30 \mathrm{mM}$ phosphate $(\mathrm{pH}$ $7.0), 1 \mathrm{mM} \mathrm{MgCl}_{2}$, and $0.05 \% \mathrm{NaN}_{3}$. After centrifugation, the supernatant was collected, dialyzed extensively against deionized water at $4{ }^{\circ} \mathrm{C}$, and lyophilized. The material was resuspended in a nuclease buffer $(10 \mathrm{mM}$ Tris, $10 \mathrm{mM}$ $\mathrm{CaCl} 2$, and $10 \mathrm{mM} \mathrm{MgCl} 2, \mathrm{pH} 7.4)$ and treated with RNase A $(0.5 \mathrm{mg} / \mathrm{ml})$, DNase $(0.1 \mathrm{mg} / \mathrm{ml})$, and RNase $\mathrm{T}_{1}$ $(5 \mu \mathrm{l} / \mathrm{ml})$ at $37^{\circ} \mathrm{C}$ for $16 \mathrm{~h}$, followed by digestion with proteinase $\mathrm{K}(0.1 \mathrm{mg} / \mathrm{ml})$ at $56^{\circ} \mathrm{C}$ for $16 \mathrm{~h}$. After centrifugation, the supernatant was collected, dialyzed extensively against deionized water; ethanol was added to a concentration of $30 \%$ and the mixture was chilled at $4{ }^{\circ} \mathrm{C}$ for at least 6 hours to precipitate contaminating nucleic acids and proteins. After centrifugation, more ethanol was added to the supernatant to $80 \%$ concentration. PSs were precipitated at $4{ }^{\circ} \mathrm{C}$ for $16 \mathrm{~h}$ and collected by centrifuga- 
tion. Nuclease treatment and 30\% ethanol precipitation were repeated until no significant amounts of proteins or nucleic acids were detected by UV absorption at $280 \mathrm{~nm}$ for protein contaminants and at $260 \mathrm{~nm}$ for nucleic acids and by ethidium bromide agarose gel for the absence of DNA.

The crude PS samples were further purified by size-exclusion and ion-exchange chromatography. The PS samples were first purified on Sephacryl S400 and S200 columns (Pharmacia Biotech, Piscataway, NJ). Eluted fractions were monitored by refractive index to detect PS and by UV absorption at $280 \mathrm{~nm}$ to detect protein contaminants. The carbohydrate content of each fraction was verified by phenol sulfuric acid assay. Fractions were also examined for immunogenicity by immunoblotting with rabbit antisera raised against the bacteria. Fractions positive with any of these four detection methods were pooled, dialyzed against deionized water, and lyophilized. They were further purified on an anion-exchange Q Sepharose column (Pharmacia Biotech, NJ), eluting with a linear gradient of $\mathrm{NaCl}$ from 0 to $1 \mathrm{M}$ in $50 \mathrm{mM}$ Tris buffer (pH 8.0). Similarly, fractions positive in the phenol-sulfuric acid assay or immunoblot were pooled, dialyzed, and lyophilized. To eliminate possible contaminants which may give false structural information, the heteroglycans were further purified by Superdex 200 column and analyzed by the same detection methods above.

\section{Chemical structural analysis of PSs}

All PS samples were analyzed by ${ }^{1} \mathrm{H}$ nuclear magnetic resonance (NMR) spectroscopy. Sample preparation consisted of $1 \mathrm{mg}$ dissolved in $0.7 \mathrm{ml}$ of $\mathrm{D}_{2} \mathrm{O}$. The spectra were acquired on a Varian Unity 500 spectrometer at $60^{\circ} \mathrm{C}$. ${ }^{1} \mathrm{H}$ chemical shifts were referenced to the HDO resonance at $4.45 \mathrm{ppm}$. The water signal was suppressed by pre-saturation during data acquisition.

Monosaccharide compositions of PSs were determined by GC-MS analysis of the alditol acetate derivatives as described [24]. In brief, $0.05 \mathrm{mg}$ of PS sample was completely hydrolyzed to monosaccharide components with $0.5 \mathrm{ml}$ of $2 \mathrm{M}$ trifluoroacetic acid at $110^{\circ} \mathrm{C}$ for $2 \mathrm{~h}$, followed by reduction to their corresponding alditols with 5 mg of $\mathrm{NaBH}_{4}$ at room temperature for $2 \mathrm{~h}$. Excess $\mathrm{NaBH}_{4}$ was removed by addition of $2 \mathrm{M} \mathrm{HCl}$ and drying under a stream of nitrogen, followed by addition of $0.5 \mathrm{ml}$ of $\mathrm{MeOH}$ and drying under nitrogen. The alditols were converted to peracetates by treatment with $1 \mathrm{ml}$ of $1: 1$ (vol.) mixture of acetic anhydride/pyridine at room temperature for $2 \mathrm{~h}$. The alditol acetate derivatives were subjected to GC-MS analysis with a DB17 column on a Hewlett-Packard 6890/5973 GC-MS instrument. The GC run was started at $180^{\circ} \mathrm{C}$, held for $2 \mathrm{~min}$, and increased to $260^{\circ} \mathrm{C}$ by $2^{\circ} \mathrm{C} / \mathrm{min}$, and held at $260^{\circ} \mathrm{C}$ for $20 \mathrm{~min}$. Standard ald- itol actetates corresponding to rhamnose, glucose, galactose, mannose, N-acetyl-glucosamine, N-acetylgalactosamine, $\mathrm{N}$-acetyl-mannosamine, and other typical monosaccharides were used for comparison in the GC-MS analysis.

\section{Preparation of antisera specific for bacterial cells or PSs}

Antisera to whole bacterial cells of E. faecalis types II and $\mathrm{V}$ and E. faecium B210860 were prepared. Bacteria were grown in $500 \mathrm{ml}$ of Todd-Hewitt broth at $37^{\circ} \mathrm{C}$ until midlog phase with $\mathrm{OD}_{650}$ of 0.4-0.5. Bacterial cells were harvested by centrifugation, washed with PBS, and fixed with $0.1 \%$ formalin at room temperature for $30 \mathrm{~min}$. Three New Zealand white female rabbits, $1.5 \mathrm{~kg}$, were used for immunization with the three strains of enterococcal cells. Rabbits were immunized intravenously with $0.1,0.3$, and $0.5 \mathrm{ml}$ of $7 \times 10^{9} \mathrm{cfu} / \mathrm{mL}$ bacterial cells on day 1,3 , and 5 , respectively. On the second, fourth, and fifth weeks, the rabbits was boosted with $0.5 \mathrm{ml}$ of the bacterial cells three times a week. Immune sera were obtained one week after the last immunization and used for identification of naturally immunogenic PSs.

Antisera against the PSs from E. faecium B210860 and E. faecalis type $\mathrm{V}$ were prepared from rabbits immunized with conjugates of PS to tetanus toxoid. For the conjugate preparation, 2-mg samples of PSs were oxidized with 0.5 $\mathrm{ml}$ of $10 \mathrm{mM} \mathrm{NaI}_{4}$ at room temperature for $90 \mathrm{~min}$, dialyzed, and lyophilized. The oxidized PS was reacted with $2 \mathrm{mg}$ of tetanus toxoid in PBS with the addition of $10 \mathrm{mg}$ of $\mathrm{NaCNBH}_{3}$. The conjugates were dialyzed and lyophilized. One New Zealand white rabbit, $1.5 \mathrm{~kg}$, was immunized with each of the two conjugates. Rabbits were immunized three times by subcutaneous injection with $50 \mu \mathrm{g}$ conjugate on weeks 1, 3, and 6. Complete Freund's adjuvant was used in the primary injection and incomplete Freund's adjuvant was used in the booster injections. Immune sera were collected one week after the last immunization and used for assessing the antigenic specificity of PSs.

\section{Fluorescence confocal microscopy}

E. faecalis type $\mathrm{V}$ and E. faecium B210860 were grown in glass-bottomed Petri dishes (MatTek, CA) with ToddHewitt broth to mid-log phase as determined by their growth curves. After being washed with PBS, bacterial cells were fixed with $1 \%$ paraformaldehyde at room temperature for $30 \mathrm{~min}$. Cells were incubated with diluted (1:250) specific antisera at $37^{\circ} \mathrm{C}$ for $90 \mathrm{~min}$, followed by incubation with Alexa Fluor 488-labeled goat-anti-rabbit IgG (Molecular Probes, CA) at $37^{\circ} \mathrm{C}$ for $90 \mathrm{~min}$. Bacterial cells were washed and viewed by fluorescence confocal microscopy (Bio-Rad 1024MP system, Zeiss axiovert S100 cryton argon laser with 488 filter). 


\section{Competitive ELISA inhibition}

Nunc-Immuno microtiter plates were coated with $100 \mu \mathrm{L}$ of the selected PS-bovine serum albumin (BSA) conjugate $(1 \mathrm{mg} / \mathrm{mL}$ for $E$. faecalis Type $\mathrm{V}$ and $0.25 \mathrm{mg} / \mathrm{mL}$ for $E$. faecium B210860) at $30^{\circ} \mathrm{C}$ for $4 \mathrm{~h}$. PS-BSA conjugates were prepared similarly to those of PS-tetanus toxoid as described above. Plates were then washed with $10 \mathrm{mM}$ Tris buffer five times. In the meantime, a series of mixing solutions were prepared on a separate plate by adding inhibitory PSs in 2-fold serial dilution. The concentrations of the PS inhibitors started at a concentration of $2.5 \mathrm{mg} /$ $\mathrm{mL}$ (10× coating-antigen) for E. faecium B210860 PS-BSA coated plates and at $10 \mathrm{mg} / \mathrm{mL}$ for E. faecalis Type V PSBSA coated plates. The mixing plates were then incubated at $30^{\circ} \mathrm{C}$ for $2 \mathrm{~h}$ and washed five times, followed by the addition of $75 \mu \mathrm{L}$ antisera to each well. For the competitive inhibition, $100-\mu \mathrm{L}$ solution containing inhibitor and antisera in the mixing plate was transferred from each well to the antigen-coated plate. The plate was incubated at $4^{\circ} \mathrm{C}$ overnight, followed by addition of $100 \mu \mathrm{L}$ alkaline phosphatase conjugated goat anti-rabbit IgG to each well. The plate was incubated at $37^{\circ} \mathrm{C}$ for $2 \mathrm{~h}$, washed five times, and $100 \mu \mathrm{L}$ of substrate solution was added containing $1 \mathrm{mg} / \mathrm{mL}$ of $p$-nitrophenyl-phosphate in bicarbonate buffer (35 mM sodium carbonate, $0.01 \% \mathrm{w} / \mathrm{w}$ $\mathrm{MgCl}_{2}, 0.02 \% \mathrm{w} / \mathrm{w}$ sodium azide, $\left.\mathrm{pH} 10\right)$. Absorption at $405 \mathrm{~nm}$ was recorded and plotted against molar concentrations of the inhibitor. Percentage of inhibition was calculated from the difference with and without inhibitor vs. control.

\section{Authors' contributions}

C. T. Hsu conducted most of the experiments and assisted in experimental design and manuscript preparation. A. L. Ganong carried out ELISA and confocal microscopy experiments. B. Reinap prepared glycoconjugates. Z. Mourelatos assisted in bacterial culture and PS isolation. J. Huebner selected and provided enterococcal strains and the type-specific sera and assisted in the PS purification process and study design. J. Y. Wang designed experiments, performed structural analyses, analyzed the data, and wrote the manuscript. All authors approved the manuscript.

\section{Acknowledgements}

We acknowledge financial support from the National Institute of Allergy and Infectious Disease of the National Institutes of Health (AI057926 and Al059500 to JYW and Al050667 to JH).

\section{References}

I. Huycke MM, Sahm DF, Gilmore MS: Multiple-drug resistant enterococci: the nature of the problem and an agenda for the future. Emerg Infect Dis 1998, 4(2):239-249.

2. Tendolkar PM, Baghdayan AS, Shankar N: Pathogenic enterococci: new developments in the 2 I st century. Cell Mol Life Sci 2003, 60(I 2):2622-2636.

3. Moellering RCJ: Vancomycin-resistant enterococci. Clin Infect Dis 1998, 26(5): $1196-1199$.
4. Klare I, Konstabel C, Badstubner D, Werner G, Witte W: Occurrence and spread of antibiotic resistances in Enterococcus faecium. Int J Food Microbiol 2003, 88(2-3):269-290.

5. Smith DL, Johnson JA, Harris AD, Furuno JP, Perencevich EN, Morris JGJ: Assessing risks for a pre-emergent pathogen: virginiamycin use and the emergence of streptogramin resistance in Enterococcus faecium. Lancet Infect Dis 2003, 3(4):24I-249.

6. Murray BE: Vancomycin-resistant enterococcal infections. $N$ Engl J Med 2000, 342(10):710-72I.

7. Woodford N: Biological counterstrike: antibiotic resistance mechanisms of Gram-positive cocci. Clin Microbiol Infect 2005, II Suppl 3:2-2I.

8. Patterson JE, Sweeney AH, Simms M, Carley N, Mangi R, Sabetta J, Lyons RW: An analysis of 110 serious enterococcal infections. Epidemiology, antibiotic susceptibility, and outcome. Medicine (Baltimore) 1995, 74(4): 191-200.

9. Pintado V, Cabellos C, Moreno S, Meseguer MA, Ayats J, Viladrich PF: Enterococcal meningitis: a clinical study of 39 cases and review of the literature. Medicine (Baltimore) 2003, 82(5):346-364.

10. van Dam JE, Fleer A, Snippe H: Immunogenicity and immunochemistry of Streptococcus pneumoniae capsular polysaccharides. Antonie Van Leeuwenhoek 1990, 58(I): I-47.

II. Jones C: Vaccines based on the cell surface carbohydrates of pathogenic bacteria. An Acad Bras Cienc 2005, 77(2):293-324.

12. Hufnagel M, Hancock LE, Koch S, Theilacker C, Gilmore MS, Huebner J: Serological and Genetic Diversity of Capsular Polysaccharides in Enterococcus faecalis. J Clin Microbiol 2004, 42(6):2548-2557.

13. Teng F, Jacques-Palaz KD, Weinstock GM, Murray BE: Evidence that the enterococcal polysaccharide antigen gene (epa) cluster is widespread in Enterococcus faecalis and influences resistance to phagocytic killing of $\mathbf{E}$. faecalis. Infect Immun 2002, 70(4):2010-20I5.

14. Xu Y, Singh KV, Qin X, Murray BE, Weinstock GM: Analysis of a gene cluster of Enterococcus faecalis involved in polysaccharide biosynthesis. Infect Immun 2000, 68(2):8I5-823.

15. Xu Y, Murray BE, Weinstock GM: A cluster of genes involved in polysaccharide biosynthesis from Enterococcus faecalis OGIRF. Infect Immun 1998, 66(9):43I3-4323.

16. Arduino RC, Murray BE, Rakita RM: Roles of antibodies and complement in phagocytic killing of enterococci. Infect Immun 1994, 62(3):987-993.

17. Theilacker C, Krueger WA, Kropec A, Huebner J: Rationale for the development of immunotherapy regimens against enterococcal infections. Vaccine 2004, 22 SuppI I:S3I-8.

18. Koch S, Hufnagel M, Theilacker C, Huebner J: Enterococcal infections: host response, therapeutic, and prophylactic possibilities. Vaccine 2004, 22(7):822-830.

19. Huebner J, Quaas A, Krueger WA, Goldmann DA, Pier GB: Prophylactic and therapeutic efficacy of antibodies to a capsular polysaccharide shared among vancomycin-sensitive and resistant enterococci. Infect Immun 2000, 68(8):463I-4636.

20. Bottone EJ, Patel L, Patel P, Robin T: Mucoid encapsulated Enterococcus faecalis: an emerging morphotype isolated from patients with urinary tract infections. Diagn Microbiol Infect Dis 1998, 3 I (3):429-430.

21. Bottone E): Encapsulated Enterococcus faecalis: role of encapsulation in persistence in mouse peritoneum in absence of mouse lethality. Diagn Microbiol Infect Dis 1999, 33(1):65-68.

22. Hancock LE, Gilmore MS: The capsular polysaccharide of Enterococcus faecalis and its relationship to other polysaccharides in the cell wall. Proc Natl Acad Sci US A 2002, 99(3): $1574-1579$.

23. Huebner J, Wang Y, Krueger WA, Madoff LC, Martirosian G, Boisot S, Goldmann DA, Kasper DL, Tzianabos AO, Pier GB: Isolation and chemical characterization of a capsular polysaccharide antigen shared by clinical isolates of Enterococcus faecalis and vancomycin-resistant Enterococcus faecium. Infect Immun 1999, 67(3):1213-1219.

24. Wang Y, Huebner J, Tzianabos AO, Martirosian G, Kasper DL, Pier GB: Structure of an antigenic teichoic acid shared by clinical isolates of Enterococcus faecalis and vancomycin-resistant Enterococcus faecium. Carbohydr Res 1999, 316(1-4):155-160.

25. Wicken AJ, Baddiley J: Structure of intracellular teichoic acids from group D streptococci. Biochem J 1963, 87:54-62. 
26. Pazur JH, Cepure A, Kane JA, Hellerquist CG: Glycans from streptococcal cell walls. The molecular structure of an antigenic diheteroglycan of glucose and galactose from Streptococcus faecalis. J Biol Chem I 973, 248(I):279-284.

27. Bleiweis AS, Young FE, Krause RM: Cell walls of group D streptococci. II. Chemical studies on the type I antigen purified from the autolytic digest of cell walls. J Bacteriol 1967, 94(5): | $38|-| 387$.

28. Hancock LE, Shepard BD, Gilmore MS: Molecular analysis of the Enterococcus faecalis serotype 2 polysaccharide determinant. J Bacteriol 2003, 185(15):4393-440I.

29. Rhinehart E, Smith NE, Wennersten C, Gorss E, Freeman J, Eliopoulos GM, Moellering RCJ, Goldmann DA: Rapid dissemination of beta-lactamase-producing, aminoglycoside-resistant Enterococcus faecalis among patients and staff on an infant-toddler surgical ward. N EnglJ Med 1990, 323(26):1814-1818.

30. Maekawa S, Yoshioka M, Kumamoto Y: Proposal of a new scheme for the serological typing of Enterococcus faecalis strains. Microbiol Immunol 1992, 36(7):67|-68I.

Publish with Bio Med Central and every scientist can read your work free of charge

"BioMed Central will be the most significant development for disseminating the results of biomedical research in our lifetime. "

Sir Paul Nurse, Cancer Research UK

Your research papers will be:

- available free of charge to the entire biomedical community

- peer reviewed and published immediately upon acceptance

- cited in PubMed and archived on PubMed Central

- yours - you keep the copyright

Submit your manuscript here:

http://www.biomedcentral.com/info/publishing_adv.asp 